\title{
A PRODUÇÃO DOS ATORES CULTURAIS DE IMPERATRIZ NA INTERNET E SUAS INTERAÇÕES COM O JORNAL O PROGRESSO
}

\section{THE PRODUCTION OF CULTURAL ACTORS IMPERATRIZ ON THE INTERNET AND THEIR INTERACTIONS WITH THE NEWSPAPER O PROGRESSO}

\author{
Thays Assunção REIS ${ }^{1}$; Sérgio Luiz GADINI ${ }^{2}$
}

Resumo: O presente trabalho pretende analisar a produção online de três atores culturais de Imperatriz-MA e averiguar se há interações entre a informação produzida por eles e a publicada pelo jornal $O$ Progresso na primeira quinzena do mês de agosto de 2015. O estudo das plataformas baseou-se na identificação dos pontos de presença na internet, periodicidade das publicações; a origem do conteúdo (próprio ou compartilhado de outros usuários) e a interação com outros usuários. Já a análise do jornal concentrou-se na identificação das matérias culturais, de modo a compreender os sentidos de cultura constituídos pelo impresso. Conclui-se que os atores culturais ainda fazem uso incipiente da web como canal de difusão e que os poderes político e econômico de Imperatriz são apontados pelo jornal como os principais produtores culturais, sendo que os demais atores culturais praticamente não aparecem ou são minimizados.

Palavras-chave: Internet; Atores Culturais; Jornal; Imperatriz; Maranhão.

\begin{abstract}
The present work intends to analyze the online production of three cultural actors Imperatriz-MA and see if there are interactions between information produced by them and published by the newspaper O Progresso in the first fortnight of August 2015. The study of the platforms it relied on the identification of points of presence on the Internet, frequency of publications; the content source (own or shared from other users) and the interaction with other users. Already the newspaper's analysis concentrated at the identification of cultural materials, to comprise the culture senses constituted by the newspaper. It is concluded that cultural actors are still incipient use of the web as a broadcast channel and that the political and economic powers of Imperatriz are appointed by the newspaper as the main cultural producers, being that the other cultural actors practically do not appear or are minimized.
\end{abstract}

Keywords: Internet; Cultural actors; Newspaper; Imperatriz; Maranhão.

\footnotetext{
${ }^{1}$ Doutoranda pelo programa de Pós-Graduação em Comunicação da Universidade do Estado do Rio de Janeiro (UERJ). E-mail: thays.jornalista@gmail.com.

2 Doutor em Comunicação e professor do Mestrado em Jornalismo da Universidade Estadual de Ponta Grossa (UEPG). E-mail: sergiogadini@yahoo.com.br.
} 


\title{
miDiA \\ 糙 DiAno
}

\section{Introdução}

É possível arriscar que esta geração é uma das mais conectadas, já que praticamente a metade dos brasileiros, $48 \%$, usa internet, sendo que o uso de aparelhos celulares - como forma de acesso à rede - já compete com computadores ou notebooks, $66 \%$ e $71 \%$, respectivamente, de acordo com dados da "Pesquisa Brasileira de Mídia 2015”. Além disso, a pesquisa revela que entre os internautas, 92\% estão conectados por meio de redes sociais, sendo as mais utilizadas o Facebook (83\%), o WhatsApp $(58 \%)$ e o Youtube $(17 \%)$.

Estes dados causam otimismo entre pesquisadores e comunicadores que depositam na internet a "esperança" de uma comunicação contra-hegemônica, horizontal e plural. É o caso de Andreu Casero, que defende a chamada "Web 2.03" como um canal privilegiado para que seus usuários desenvolvam e controlem seus próprios processos e intercâmbios comunicativos.

\begin{abstract}
El nuevo rol de la ciudadanía, gracias a la Web 2.0, puede desencadear abudantes alteraciones em la esfera pública y la dinámica polítcia. Cuatro son los procesos, ligados al universo 2.0, que abren uma vía de transformación del escenario actual de la comunicación politica. Se trata del aumento de la pluralidade de vocês, del surgimento de la cultura de la colaboración y del periodismo ciudadano, de la emergencia del ciudadano vigilante y de la aparición del súper-usuario (CASERO, 2010, p. 109-110)
\end{abstract}

Para Dênis de Moraes (2007), os usuários da internet têm a chance de atuar, simultaneamente, como produtores, emissores e receptores, dependendo de lastros culturais e habilidades técnicas. Dessa forma, publicar e disponibilizar conteúdo para milhões de pessoas, que anteriormente era privilégio de grandes empresas ou governos devido aos altos custos com produção, impressão e distribuição, agora é possível a todos aqueles que tiverem um computador ou celular, uma conexão com a internet e uma conta gratuita em uma rede social ou plataforma de blogs.

Mas, apesar das suas potencialidades, a internet ainda não é acessível à grande parte da população adulta do globo. Segundo Maia (2008), a pobreza, a precariedade das infraestruturas de comunicação ou, ainda, a falta de habilidades e de treinamento

\footnotetext{
${ }^{3} \mathrm{O}$ termo A Web 2.0 foi criado por Tim O'Reilly para designar a segunda geração de serviços online, que caracterizam-se por potencializar as formas de publicação, compartilhamento e organização de informações, além de ampliar os espaços para a interação entre os participantes do processo.
} 


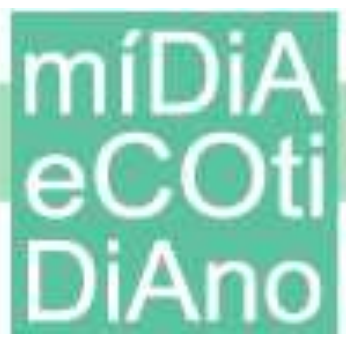

digital são fatores que impossibilitam o acesso dos cidadãos às discussões em rede. Além disso, a apatia política e a falta de motivação das pessoas para informar-se, a fim de compreenderem as questões relacionadas aos negócios públicos e aos interesses do jogo político, também contribuem para que a internet seja utilizada apenas como um canal de entretenimento.

Nesse sentido, Maia (2008) destaca a importância dos atores sociais coletivos sindicatos, organizações não governamentais, associações de moradores, grupos culturais e outros setores da sociedade civil - no processo de superação da ignorância política e no aperfeiçoamento da capacidade crítica, bem como na construção de um conhecimento próprio.

Percebe-se, então, que milhares de grupos e comunidades virtuais surgem no ciberespaço com os mais variados propósitos, dentre eles estão: a) interpretação de interesses e construção de identidade coletiva; b) constituição de esfera pública; c) ativismo político, embates institucionais e partilha de poder; d) supervisão e processos de prestação de contas (MAIA, 2008, p. 337).

Com base nestas reflexões, o presente trabalho busca saber como as organizações culturais de Imperatriz (localizada no sudoeste do Maranhão, próximo aos estados do Pará e Tocantins) exploram as redes digitais e com que propósito? São explicitadas interações entre informação produzida por estes atores no ambiente virtual e a publicada pelo jornal $O$ Progresso?

No intuito de responder a estes questionamentos a investigação se viabiliza por meio de uma identificação das plataformas de conteúdo online (Facebook, Twitter, Youtube, blogs, sites, portais, fóruns de discussão e serviços de publicação de fotografia) de três atores culturais imperatrizenses - Espaço Cultura, Centro de Cultura Negra Negro Cosme e Casa das Artes - seguida pela observação dos seguintes aspectos: a periodicidade das publicações; a origem do conteúdo (próprio ou compartilhado de outros usuários); a interação com outros usuários. Também realizou-se um cruzamento do conteúdo produzido pelos atores culturais nas redes digitais com o publicado no jornal O Progresso durante a primeira quinzena do mês de agosto de 2015. 


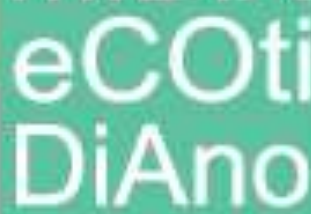

A escolha do jornal $O$ Progresso de Imperatriz- $\mathrm{MA}^{4}$ foi por ser o mais antigo impresso em circulação na cidade e destinar espaços aos produtos culturais. Trata-se de um impresso de uma cidade de porte médio, com cerca de 252.320 mil habitantes (IBGE, 2015).

O jornal tem alcance regional e circula em cidades do sul do Pará e também no norte do Tocantins, além de municípios do oeste do Maranhão. O jornal O Progresso é diário, porém não circula às segundas-feiras. Possui dois cadernos: principal e o segundo caderno, somando em torno de quatorze páginas. O primeiro envolve as matérias locais, policiais e políticas. O segundo traz a cobertura esportiva e também notícias gerais e regionais. Há um terceiro caderno, aos domingos, com material sobre novelas, cruzadas, horóscopo e dicas culturais. Nele é publicada também uma página da Academia Imperatrizense de Letras (AIL) com a produção de um dos associados no Caderno Extra.

Figura 1 - Capa do Jornal O Progresso

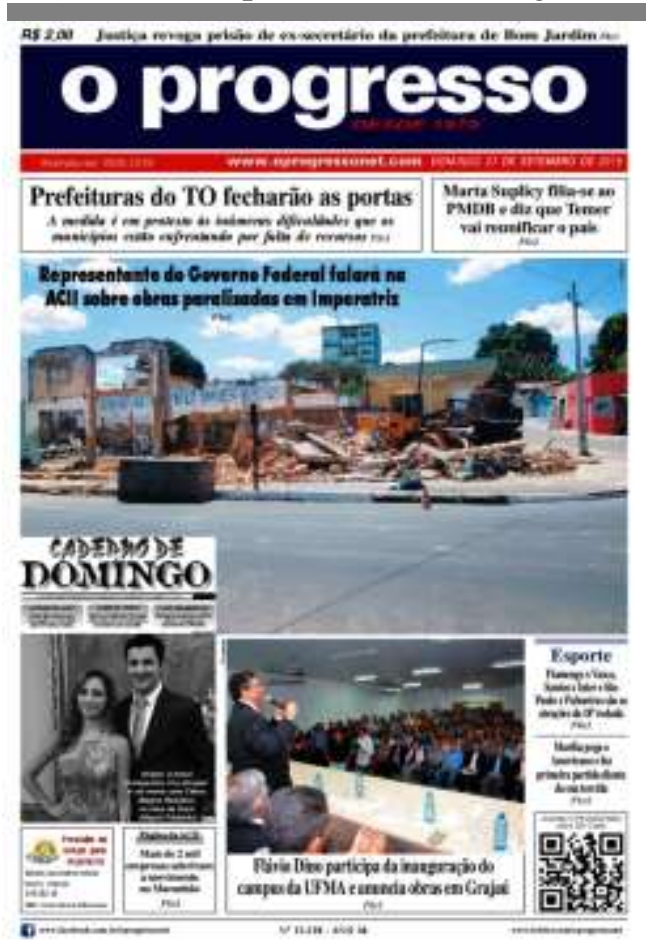

Fonte: http://www.oprogressonet.com/

\footnotetext{
4 O jornal O Progresso foi fundado em 3 de maio de 1970, em Imperatriz-MA, pelo empresário gráfico José Matos Vieira e pelo jornalista Jurivê de Macedo. Posteriormente foi vendido e teve vários proprietários. Hoje tem como diretor superintendente Sérgio Godinho. O jornal se caracteriza pelo destaque às matérias de política e polícia. No tocante à cobertura política, é comum a publicação de material jornalístico enviado pelo poder municipal através das assessorias de imprensa.
} 
Quanto ao cenário cultural, Imperatriz é caracterizada pela presença de festas oficiais de Carnaval e São João, pelo movimento de grupos teatrais no Teatro Ferreira Gullar, o único da cidade, pelos produtos audiovisuais das redes de cinema, pelas iniciativas da Academia Imperatrizense de Letras (AIL) e da Fundação Cultural, pela produção do Núcleo Imperatrizense de Cinema (Nice), e por projetos alternativos na área cultura, entre outras ações.

Além disso, existem profissionais que estão diretamente relacionados com as atividades culturais em Imperatriz - produtores, atores, músicos, escritores, artesãos, dançarinos, entre outros. Segundo a Fundação Cultural de Imperatriz ${ }^{5}$, existem no munícipio cerca de 20 produtores, 30 grupos de dança, 10 músicos, 05 pintores, 08 quadrilhas juninas.

A cidade possui aproximadamente 70 artesãos regularmente vinculados à Associação de Artesãos de Imperatriz (Assari) que expõem suas produções no Centro de Artesanato, localizado em frente a Praça da Cultura, e em um shopping da cidade. E ainda ela conta com a presença das companhias de teatro Arte Ceb, ArteBack, Okazajo, Repes e Ruáh.

Quanto ao número de escritores, a Academia de Letras agrega 40 membros eleitos e efetivos, sendo todos escritores regionais com produção reconhecida no campo cultural. Dentre os principais nomes, podemos mencionar: Edmilson Sanches, Adalberto Franklin, Edelvira Barros, Livaldo Fregona e Agostinho Noleto.

Com base nesta realidade e nos limites do texto, a investigação se concentrará apenas no Centro de Cultura Negra Negro Cosme (CCN/NC), Associação Casa das Artes e o Projeto Espaço Cultura. O primeiro realiza iniciativas culturais com o objetivo de combater a discriminação étnico-racial. Entre as atividades desenvolvidas pela instituição estão: Mostra e Interpretação de Música Negra, Festival de Interpretação Teatral da Literatura Negra - Poema, Conto, Crônica e Dramaturgia (Festiafro), Dia de Leitura na Praça: Uma pausa para refletir sobre o racismo, Concurso de Desenhos Afro-

\footnotetext{
${ }^{5}$ A quantidade foi baseada em uma lista telefônica do órgão consultado, pois o mesmo não dispõe de um cadastro sistematizado com as informações sobre os atores culturais. Neste sentido, o número expresso deve ser maior.
} 


\title{
ecot DiAno
}

Brasileiros, Semana Municipal da Consciência Negra e a realização de palestras em escolas, empresas e universidades públicas e privadas.

A Associação Cultural Casa das Artes também cria canais para melhoria da qualidade de vida das diversas comunidades marginalizadas da sociedade imperatrizense e da região tocantina, por meio da produção de eventos artístico-culturais e da formação para produção e veiculação dos bens, serviços e produtos culturais e educativos, propondo a efetividade de políticas públicas. E o projeto Espaço Cultura realiza atividades em quatro setores de atuação: La Oficina (cursos e treinamento nas áreas de comunicação e arte), Projeto Escola (escolas públicas e particulares), Sala Filmes (exibição de filmes nacionais, europeus e clássicos) e eventos culturais.

\section{Ativismo em rede e a articulação dos atores culturais}

Ao desenvolver seus estudos, Luiz Beltrão (1980) apontou para a existência de uma comunicação cotidiana, que não apenas expressa ideias de determinados grupos, mas representa uma forma de ação ou contestação aos valores hegemônicos sociais ou culturais. Neste contexto, o autor emprega o conceito de "líder de opinião" para se referir ao agente responsável pela decodificação das mensagens para a audiência. Porém, esta definição foi atualizada por Osvaldo Trigueiro (2006) e deu lugar às práticas dos indivíduos como uma forma de ativismo e participação na esfera pública através de meios informais de comunicação. Para o autor,

\begin{abstract}
o ativista midiático age motivado pelos seus interesses e do grupo social ao qual pertence na formação das práticas simbólicas e materiais das culturas tradicionais e modernas para o uso da vida cotidiana. É um narrador da cotidianidade, guardião da memória e da identidade local, reconhecido como porta-voz do seu grupo social e transita entre as práticas comunicacionais tradicionais e as modernas, apropria-se das novas tecnologias de comunicação para fazer circular as narrativas populares nas redes globais (TRIGUEIRO, 2006, p. 03).
\end{abstract}

Dessa forma, o ativista potencializa os produtos culturais populares e contribui com as lutas pela cidadania, visto que ele pode transitar nas esferas informais da produção cultural popular e nas esferas oficiais ou institucionais, "realizando as conexões entre as experiências do seu mundo e as de outros notadamente ao vivo, pelo rádio e pela televisão" (TRIGUEIRO, 2006, p. 06). 
Nesse novo espaço se reconhece a importância dos ativistas midiáticos dos sistemas folkcomunicacionais que atuam nos movimentos participativos da cidadania, como agentes comunicadores vinculados aos movimentos culturais que utilizam estratégias, que legitimam a sua participação como cidadãos conscientes do seu papel na organização da sociedade civil. Esses atores sociais operam dispositivos de comunicação das redes de cooperação e solidariedade entre pessoas, grupos e comunidades de convivência, pró ximos uns dos outros, e que estão vinculados por laços de parentesco, pela vizinhança, história de vida, encontrando na rede de solidariedade uma alternativa de sobrevivência social. (TRIGUEIRO, 2006, p.10).

$\mathrm{Na}$ mesma perspectiva, John Downing ${ }^{6}$ emprega o conceito de mídia radical para caracterizar as iniciativas comunicacionais fora dos limites da oficialidade, e que acabam por constituir uma "esfera pública alternativa". Isso pode ser observado no uso da internet pelos grupos culturais de Imperatriz - Facebook, Youtube, blogs, Instagram, Twitter, sites etc - que revela uma nova forma de ativismo midiático, não mais atrelada à centralidade dos meios de comunicação tradicionais.

Por sua vez, Castells (2013) comenta que as redes sociais digitais baseadas na internet e nas plataformas sem fio são ferramentas decisivas para o desenvolvimento deste novo ativismo midiático, já que elas possibilitam aos movimentos a capacidade de mobilização, organização, deliberação, coordenação e decisão. Além disso, o autor assegura que "o papel da internet ultrapassa a instrumentalidade: ela cria as condições para uma forma de prática comum que permite ao movimento sem liderança sobreviver, deliberar, coordenar e expandir-se" (CASTELLS, 2013, p. 171).

No caso do uso das redes digitais pelos três atores culturais imperatrizenses, verificou-se que todos possuem uma página no Facebook. Além desta ferramenta, o Centro de Cultura Negra (CCN) possui um blog e uma conta no Twitter; a Casa das Artes conta com um blog, um site do Projeto Circolando (contemplado pelo prêmio Carequinha/2014), e outro site da instituição em desenvolvimento; o Espaço Cultura possui conta no Instagram e um canal no Youtube.

A presença nas redes não significa que todas estejam ativas, por exemplo, o Twitter do CCN e o blog da Casa das Artes estão desatualizados desde 2010. Quanto à periodicidade das atualizações nas fanpages durante os quinze primeiros dias de agosto de 2015, a página da CNN não foi atualizada; a da Casa das Artes deixou de ser

\footnotetext{
${ }^{6}$ O termo mídia radical, formulado por John Downing (2003), designa a mídia que expressa uma visão alternativa às políticas, prioridades e perspectivas hegemônicas.
} 


\section{míDiA \\ eCo \\ DiAno}

atualizada nove dias, com a ausência de conteúdo mais de três dias consecutivos; e a do Espaço Cultura teve dez dias sem nenhuma postagem, sendo que houve casos de três dias seguidos entre uma postagem e outra de conteúdo. Por outro lado, o Instagram do Espaço Cultura teve um índice de desatualização menor, apenas seis dias a conta não foi alimentada com conteúdo.

Já a periodicidade do site do Projeto Circolando, do blog do CNN e da conta do Youtube do Espaço Cultura seguem uma lógica de publicação irregular, com mais de um mês sem a postagem de informações. $\mathrm{O}$ site foi alimentado pela última vez em julho de 2015 com clippings de matérias publicadas nos jornais do munícipio, o blog teve sua última postagem em de junho de 2015 e a conta do Youtube registrou um novo vídeo em 31 de março de 2015.

Considerando estas informações, verifica-se que a Web 2.0, entendida como o "conjunto de tecnologias vinculadas à internet que permitem aos usuários desenvolver, protagonizar e controlar seus próprios processos e intercâmbios comunicativos graças à interatividade" (CASERO, 2010, p. 109), é pouco aproveitada pelos movimentos culturais imperatrizenses no sentido da produção e difusão de suas mensagens visto que não há uma atualização recorrente das redes.

Sobre a origem do material dessas redes, o $\mathrm{CNN}$ publicou informações especificamente sobre atividades da própria entidade, assim como o Espaço Cultura. Já a Casa das Artes postou material próprio, como fotos de oficinas do Projeto Circolando, e compartilhou conteúdo de outros usuários - editais de apoio à cultura e notícias culturais. Portanto, os grupos culturais de Imperatriz utilizam a comunicação mediada por computador para expressar e atualizar suas identidades, seus valores e interesses, como aponta Rousiley Maia (2008).

A interação com o público é ausente no Facebook do $\mathrm{CNN}$, visto que não houve publicações no período da pesquisa. Na fanpage da Casa das Artes também não aconteceu uma interação ativa da instituição com o público, porém, em períodos anteriores percebeu-se a presença de algumas respostas da Casa das Artes aos comentários do público, principalmente quando o assunto eram as oficinas do Projeto Circolando. O Espaço Cultura é a organização que mais interage com seu público, tanto 


\section{ecot \\ DiAno}

no Facebook como no Instagram, sempre publicando respostas/esclarecimentos nos comentários.

Dessa maneira, observa-se que mesmo essas tecnologias sendo vinculadas a web 2.0, elas não desenvolvem uma cultura colaborativa e cooperativa. Os cidadãos imperatrizenses não vêem no espaço online das referidas entidades culturais um local para debate público a cerca dos processos e dinâmicas culturais da cidade e região tocantina.

Apesar das "deficiências" no uso das redes digitais, todas as organizações reconhecem na internet um espaço privilegiado para ampliar o poder de comunicar. $\mathrm{O}$ CNN, por exemplo, conseguiu recentemente o apoio de um jornalista para o desenvolvimento das ações da assessoria, que inclui a potencialização e ampliação de ferramentas no ambiente virtual. A Casa das Artes também está com um novo site em desenvolvimento e o Espaço Cultura é o único que tem conseguido explorar um pouco melhor as redes digitais, visto que o projeto conta desde o início com o auxílio de uma estudante de jornalismo.

\section{Nas páginas do jornal $O$ Progresso}

Em relação à segunda questão deste estudo, ou seja, sobre as interconexões entre o conteúdo produzido pelos grupos culturais analisados e o publicado pelo jornal $O$ Progresso no decorrer da primeira quinzena de agosto, estas quase não são encontradas. Entre as 48 matérias de cultura registradas no período mencionado, apenas cinco fazem referência às organizações (M20, M22, M23, M43, M45), sendo que as ações do Espaço Cultura são as com mais expressividade no impresso (M20, M22, M43, M45), seguida pela Casa das Artes (M23). O Centro de Cultura Negra não foi citado pelo impresso em nenhuma matéria ou nota.

É interessante mencionar que os temas pautados no jornal dialogam com as publicações das redes dos dois grupos culturais, mas isso não significa que a produção virtual influenciou na tematização do jornal, já que as informações contidas nas páginas do impresso são realeses feitos pelas assessorias. Portanto, o diálogo do jornal com os agentes culturais da cidade restringe-se àqueles que possuem uma assessoria de 


\section{PPGMC}

\section{DiAno}

imprensa, ou seja, os que não têm um profissional que divulgue suas ações acabam por serem excluídos do impresso ou terem sua visibilidade limitada a eventos esporádicos.

Sobre este cenário, Ballerini (2015) comenta que a lógica de produção de reportagens/matérias nos impressos têm se limitado apenas às sugestões de pautas de assessorias. "Diversos cadernos culturais resignam-se a simplesmente divulgar, por exemplo, filmes que estão estrelando, sem lançar um olhar próprio e independente sobre tal suporte" (BALLERINI, 2015, p.62).

Tabela 1 - Notícias publicadas entre 1 a 15 de agosto de 2015

\begin{tabular}{|c|c|c|c|}
\hline Data & Espaço & Título & Matéria \\
\hline 02.08 & Regional & VLI na Exposição Agropecuária de Porto Franco & M1 \\
\hline 02.08 & Cidade & $\begin{array}{c}\text { Violinista Turíbio Santos é o primeiro artista com presença } \\
\text { confirmada no } 13^{\circ} \text { Salimp }\end{array}$ & M2 \\
\hline 02.08 & Cidade & $\begin{array}{l}\text { Imperatriz recebe oficina para três editais do Ministério da } \\
\text { Cultura }\end{array}$ & M3 \\
\hline 02.08 & Cidade & Aniversário do Programa A gente vê com Tereza Eugênia & M4 \\
\hline 02.08 & $\begin{array}{l}\text { Caderno } \\
\text { extra, capa }\end{array}$ & Ex-eternos amores & M5 \\
\hline 02.08 & $\begin{array}{l}\text { Espaço das } \\
\text { Letras, capa }\end{array}$ & Só faz assim como eu faço & M6 \\
\hline 02.08 & $\begin{array}{l}\text { Caderno de } \\
\text { domingo }\end{array}$ & Os benefícios da massagem & M7 \\
\hline 02.08 & $\begin{array}{l}\text { Caderno de } \\
\text { domingo }\end{array}$ & Pôster Perfil - Rodrigo Lombardi & M8 \\
\hline 02.08 & $\begin{array}{l}\text { Caderno de } \\
\text { domingo }\end{array}$ & "Cúmplices de um resgate" é a nova aposta do SBT & M9 \\
\hline 02.08 & $\begin{array}{l}\text { Caderno de } \\
\text { domingo }\end{array}$ & TV paga - destaques & M10 \\
\hline 02.08 & $\begin{array}{l}\text { Caderno de } \\
\text { domingo }\end{array}$ & Resumo das Novelas & M11 \\
\hline 02.08 & $\begin{array}{l}\text { Caderno de } \\
\text { domingo }\end{array}$ & Dicas de livro, CD e DVD & M12 \\
\hline 04.08 & Cidade & Evento leva cultura do hip hop para shopping de Imperatriz & M13 \\
\hline 04.08 & Cidade & $\begin{array}{c}\text { Movimento de banhistas nas praias de Imperatriz gera renda } \\
\text { a trabalhadores de diversos segmentos }\end{array}$ & M14 \\
\hline 05.08 & Cidade & $\begin{array}{l}\text { Funcionamento de casas noturnas será debatido hoje em } \\
\text { audiência pública }\end{array}$ & M15 \\
\hline 05.08 & Regional & $\begin{array}{c}\text { Projeto Esportivo de Imperatriz é apoiado pela lei de } \\
\text { incentivo ao Esporte e Cultura }\end{array}$ & M16 \\
\hline 05.08 & Tocantins & $\begin{array}{c}\text { Praia de Mirassol reúne mais de } 30 \text { mil pessoas durante a } \\
\text { temporada de férias } 2015\end{array}$ & M17 \\
\hline 06.08 & Cidade & $\begin{array}{l}\text { Câmara discute mudança na lei que regulamenta } \\
\text { funcionamento de casas noturnas }\end{array}$ & M18 \\
\hline
\end{tabular}




\begin{tabular}{|c|c|c|c|}
\hline 06.08 & Regional & Mariozan Rocha agita multidão na praia da Sumaúma & M19 \\
\hline 06.08 & $\begin{array}{l}\text { Publicações } \\
\text { Legais }\end{array}$ & Antiquário das Raposas & M20 \\
\hline 07.08 & Cidade & $\begin{array}{c}\text { Alameda Guilherme Cortez servirá de espaço para } \\
\text { apresentações culturais }\end{array}$ & M21 \\
\hline 07.08 & Geral & $\begin{array}{c}\text { Final do circuito brasileiro de League of Legends será } \\
\text { exibida em Imperatriz }\end{array}$ & M22 \\
\hline 07.08 & Geral & $\begin{array}{c}\text { Atriz maranhense apresenta espetáculo dedicado a Cora } \\
\text { Coralina }\end{array}$ & M23 \\
\hline 08.08 & $\begin{array}{l}\text { Coluna Fora } \\
\text { da Pauta }\end{array}$ & $\begin{array}{c}\text { Dia dos pais no Imperial Shopping Center com apresentação } \\
\text { da Banda senzala Reggae }\end{array}$ & M24 \\
\hline 08.08 & $\begin{array}{l}\text { Coluna Fora } \\
\text { da Pauta }\end{array}$ & Os pais & M25 \\
\hline 08.08 & $\begin{array}{l}\text { Coluna Fora } \\
\text { da Pauta }\end{array}$ & Bazar Beauty & M26 \\
\hline 09.08 & $\begin{array}{l}\text { Coluna Fora } \\
\text { da Pauta }\end{array}$ & Praias de Imperatriz & M27 \\
\hline 09.08 & Cidade & $\begin{array}{c}\text { População deseja que Praça da Cultura seja "espelho" da } \\
\text { Praça Mary de Pinho }\end{array}$ & M28 \\
\hline 09.08 & Cidade & $\begin{array}{l}\text { Praias serão destinos escolhidos para a comemoração do Dia } \\
\text { dos pais }\end{array}$ & M29 \\
\hline 09.08 & Cidade & Forró Pinotti na Praia de Sumaúma & M30 \\
\hline 09.08 & $\begin{array}{l}\text { Caderno Extra } \\
\text { - capa }\end{array}$ & Ambientalista pede socorro para salvar o rio Tocantins & M31 \\
\hline 09.08 & $\begin{array}{l}\text { Espaço das } \\
\text { letras - capa }\end{array}$ & A Thomas Merton & M32 \\
\hline 09.08 & $\begin{array}{l}\text { Caderno de } \\
\text { Domingo }\end{array}$ & A beleza nos pequenos detalhes & M33 \\
\hline 09.08 & $\begin{array}{l}\text { Caderno de } \\
\text { Domingo }\end{array}$ & Pôster Perfil - Maurício Destri & M34 \\
\hline 09.08 & $\begin{array}{l}\text { Caderno de } \\
\text { Domingo }\end{array}$ & $\begin{array}{l}\text { Ticiana Villas Boas, a bela do "Back off Brasil" - Mão na } \\
\text { massa }\end{array}$ & M35 \\
\hline 09.08 & $\begin{array}{l}\text { Caderno de } \\
\text { Domingo }\end{array}$ & TV paga - destaques & M36 \\
\hline 09.08 & $\begin{array}{l}\text { Caderno de } \\
\text { Domingo }\end{array}$ & Resumo das Novelas & M37 \\
\hline 11.08 & Cidade & $\begin{array}{c}\text { "Chapeuzinho Vermelho ou O Diário do Lobo mau" será } \\
\text { apresentado hoje em Imperatriz }\end{array}$ & M38 \\
\hline 12.08 & Cidade & $\begin{array}{l}\text { Lei dos Bares será discutida e votada na Câmara de } \\
\text { Vereadores }\end{array}$ & M39 \\
\hline 13.08 & Cidade & $\begin{array}{l}1^{\text {a }} \text { Feijoada Motoimp será realizada neste sábado, já entrando } \\
\text { no clima do evento }\end{array}$ & M40 \\
\hline 13.08 & Cidade & Banhistas elogiam estrutura das praias de Imperatriz & M41 \\
\hline 14.08 & Cidade & $\begin{array}{l}\text { Projeto Arte \& Cidadania nas escolas será lançado na } \\
\text { Fundação Cultural }\end{array}$ & M42 \\
\hline 14.08 & Cidade & Anima Sul 2015 começa neste sábado em Imperatriz & M43 \\
\hline 15.08 & $\begin{array}{l}\text { Coluna Fora } \\
\text { da Pauta }\end{array}$ & Capoeira no Imperial & M44 \\
\hline
\end{tabular}




\begin{tabular}{|c|c|c|c|}
\hline 15.08 & $\begin{array}{c}\text { Coluna Fora } \\
\text { da Pauta }\end{array}$ & Anima Sul vem aí & M45 \\
\hline 15.08 & $\begin{array}{c}\text { Coluna Fora } \\
\text { da Pauta }\end{array}$ & Encontro de Skatistas no Imperial Shopping & M46 \\
\hline 15.08 & Cidade & Segunda Edição do Cacau Pop Rock chega à etapa final & M47 \\
\hline 15.08 & Cidade & $\begin{array}{c}\text { Academia Imperatrizense de Letras realiza noite cultural em } \\
\text { Sítio Novo }\end{array}$ & M48 \\
\hline
\end{tabular}

Fonte: Elaboração própria

Nas páginas de $O$ Progresso são recorrentes as referências aos agentes culturais institucionalizados, como a Academia Imperatrizense de Letras (AIL), ou as personalidades que articulam posições através de textos publicados em espaços especiais no jornal: a página da AIL aos domingos e o Caderno Extra. São poetas, políticos e cantores com carreiras reconhecidas e que ressaltam suas produções literárias ou leituras de mundo nas páginas do jornal (M2, M5, M6, M31, M32 e M48). Dessa forma, suas percepções e trajetórias são legitimadas e referenciadas como exemplos no campo cultural.

A prefeitura municipal, representada pela Fundação Cultural, e o Imperial Shopping Center também são apontados na cobertura jornalística como os principais produtores culturais. Assim, a cultura apresentada pelo impresso está atrelada aos interesses políticos e econômicos do munícipio, que acabam por apontar o que é cultura e delimitar os espaços da ação cultural:

Neste sábado o Centro Cultural Senzala de Capoeira estará no Imperial Shopping realizando ações e divulgando a expressão cultural brasileira para os presentes. Durante o evento, que deve começar a partir das $15 \mathrm{~h}$, na praça de eventos do shopping, o público vai poder conferir apresentações realizadas pelo grupo, além de uma exposição comos principais instrumentos utilizados na capoeira. Vale a pena conferir! (Jornal O Progresso, M44, grifo nosso).

Por outro lado, o jornal indica em suas páginas espaços de circulação e consumo cultural que fogem do circuito de shoppings centers, centros de artes, casas de shows ou ambientes universitários. É o caso das praias de Imperatriz e região que, no período de veraneio - entre julho e setembro - se tornam referências de diálogo e ação cultural.

As praias de Imperatriz e de outras cidades da região estão entre os destinos escolhidos por várias famílias que pretendem comemorar o Dia dos Pais fora de casa. A data, que destaca a importância da figura que representa para os filhos a coragem, a força e bravura diante dos problemas do dia a dia, não vai pas sar em 
branco se depender dos imperatrizenses. "Minha família escolheu me levar, é isso mesmo, eles é quem vão me levar para a Praia do Cacau, disseram vai ser logo cedo, antes de amanhecer direito, para aproveitar até o final da tarde. Já preparam churrasqueira, bebida, tá sendo um corre-corre hoje e eu aqui só olhando o movimento e esperando a hora", comenta o aposentado João Luís, do bairro Nova Imperatriz. (O Progresso, M29, grifo nosso).

Outro aspecto digno de nota é que o jornal, em uma cidade com indústria cultural insipiente, dá respaldo ao consumo de produtos culturais (canais a cabo, novelas, artistas, livros, shows etc) produzidos em outras realidades socioeconômicas. Essa competência para gerar bens culturais é atribuída às emissoras de TV, à indústria editorial e aos mercados musical e audiovisual. Tais referências culturais ganham destaques aos finais de semana, com edições ampliadas e novos cadernos.

Neste contexto, $O$ Progresso cria uma realidade de uma cidade desprovida de cenas culturais diversificadas ou múltiplas, pois o jornal retrata que o consumo cultural ora é decidido pelos poderes públicos e econômicos ou pela indústria cultural que não dialoga com a realidade local, com suas mercadorias estandardizadas e decididas fora dos contextos regionais.

Oportuno considerar que esta realidade está diretamente relacionada com processo produtivo do Progresso. O impresso, por possuir um grande volume de matérias oriundas de assessorias imprensa publicadas em suas páginas, dispõe de uma produção autoral pouco profissionalizada. Isso torna-se evidente quando o editor do impresso, Coriolano Filho, considera a presença das matérias de assessoria uma forma de contribuição para a cultura da cidade. "Todo release que a gente recebe, nós publicamos! Até porque se o jornal não publicar os releases, ele está se negando a colaborar com a cultura" (REIS, 2017, p.109-110). Neste sentido, infere-se que essa lógica faz com que o jornal não utilize as redes sociais (facebook e twitter, as mais acessadas) e outras plataformas digitais para a produção de conteúdo.

\section{Considerações finais}

A partir do levantamento, observa-se que, apesar de todos os agentes culturais investigados terem pelo menos um ponto de presença na internet, o uso da web como canal de comunicação ainda é pouco explorado. Mesmo quando alguma organização utiliza a internet constantemente, a produção do conteúdo fica restrita a eventos, sendo 


\section{eco \\ DiAno}

que os grupos poderiam usar as ferramentas como um espaço de formação e mobilização para as questões culturais do munícipio.

Além disso, o estudo identificou que as plataformas mais bem utilizadas são aquelas que contam com presença de um profissional ou estudante de comunicação que desenvolva o serviço de assessoria. Logo, para efetivar o potencial emancipatório e transformador da internet, é preciso promover a capacitação comunicativa dos movimentos culturais.

Quanto ao espaço destinado à cultura no jornal O Progresso, observa-se que a política e os interesses econômicos ainda atravessam permanentemente a cena cultural no impresso. Os demais agentes culturais, como Casa das Artes e Centro de Cultura Negra, praticamente não aparecem ou são minimizados. Dessa forma, os poderes político e econômico sinalizam, através das matérias jornalísticas, os sentidos de cultura, os espaços e onde estão agentes e serviços culturais.

A capacidade de atuação e articulação no campo cultural (eventos, mobilizações, ocupação de espaços públicos, produção literária, entre outros) é atribuída aos poderes públicos e segmentos sociais institucionalizados. Além disso, agentes do campo literário, reconhecidos e alguns atrelados ao poder instituído, são referendados com espaços para suas produções literárias.

O jornal citado encampa, por outro lado, a indústria cultural nacional, em espaços editorais especiais e cadernos. Há destaque para a divulgação de produtos televisivos ou audiovisuais (novelas, TV paga, perfis de artistas, livros, CDs, DVDS etc). Não há indicação no discurso analisado da indústria cultural local, cujos traços não aparecem na cobertura jornalística.

Por fim, o discurso jornalístico tende para duas ideias centrais: a) a competência dos poderes municipais e econômico (a exemplo das prefeituras e shoppings centers) como um dos agentes principais do campo cultural e b) a competência da indústria cultural como geradora dos principais bens a serem consumidos pelos leitores na atualidade. O jornalismo cultural, ora praticado, não envolve sujeitos da sociedade civil ou de grupos destituídos de poder político ou econômico como atores capazes de participar da cena cultural. Portanto, os significados sobre o campo cultural agregam oficialismo, silêncios e poder hegemônico. 


\section{Referências}

BALLERINI, Franthiesco. Jornalismo cultural no século 21: literatura, artes visuais, teatro, cinema e música: a história, as novas plataformas, o ensino e as tendências na prática. São Paulo, Summus: 2015.

BELTRÃO, Luiz, Folkcomunicação: a comunicação dos marginalizados. São Paulo: Cortez, 1980.

CASERO, Andreu. El despertar del público? Comunicación política, ciudadanía y web 2.0. In: VICENTE, Maximiliano Martin; ROTHBERG, Danilo (orgs.). Meios de comunicação e cidadania. São Paulo: Cultura Acadêmica, 2010.

CASTELLS, Manuel. Redes de indignação e esperança: movimentos sociais na era da internet. Rio de Janeiro: Zahar, 2013.

DOWNING, John. Mídia radical. São Paulo: SENAC, 2003.

INSTITUTO BRASILEIRO DE GEOGRAFIA E ESTATÍSTICA. Cidades. In: http://www.cidades.ibge.gov.br/xtras/perfil.php?lang=\&codmun=210530\&search=maranhao/im peratriz. Acesso em 10 de agosto de 2015.

JORNAL O PROGRESSO. O início. In: http//www.oprogressonet.com/institucional/oinicio.html. Acesso em 08 de agosto de 2015.

MAIA, Rousiley. Redes cívicas e internet: efeitos democráticos do associativismo. In: GOMES, Wilson; MAIA, Rousiley. Comunicação e democracia: problemas \& perspectivas. São Paulo: Paulus, 2008.

MORAES, Dênis de. Comunicação alternativa, redes virtuais e ativismo: avanços e dilemas. Revista Eletrónica Internacional de Economía Política de las Tecnologías de la Información y la Comunicación (Eptic). Vol. IX, n. 2, mayo-ago/2007. Disponível em: http://www.seer.ufs.br/index.php/eptic/article/view/226/224.

Pesquisa brasileira de mídia 2015. Hábitos de consumo de mídia pela população brasileira. Brasilia: SeCom, 2015. Disponível em: http://www.secom.gov.br/atuacao/pesquisa/lista-depesquisas-quantitativas-e-qualitativas-de-contratos-atuais/pesquisa-brasileira-de-midia-pbm2015.pdf.

REIS, Thays Assunção. A cultura nos diários maranhenses: uma análise editorial dos jornais O Estado do Maranhão, O Imparcial, Pequeno e O Progresso. Dissertação (Mestrado em Jornalismo). Universidade Estadual de Ponta Grossa, Ponta Grossa, 2017.

TRIGUEIRO, Osvaldo. O ativista midiático da rede folkcomunicacional. Revista Internacional de Folkcomunicação, vol. 4, n. 7, 2006. Disponível em: http://www.revistas.uepg.br/index.php?journal=folkcom\&page=article\&op=viewFile\&path[]=5 $36 \&$ path[] $=370$ 